\title{
Etiology and Antimicrobial Susceptibility Patterns of Urinary Tract Infection at Dhaka Shishu (children) Hospital
}

\author{
M A Islam ${ }^{1}$, J Ahmed ${ }^{2}$, B H N Yasmeen ${ }^{3}$, M M Z Islam ${ }^{4}$, N Nahar ${ }^{5}$
}

Abstract

Background : Urinary tract infection (UTI) is a common bacterial disease in infant and childhood period that can present as symptomatic or asymptomatic way.Antibiotic resistance of urinary tract pathogens has been known to increase worldwide, especially to commonly used antimicrobials. Knowledge of pathogens causing UTI and their antimicrobial resistance patterns in a specific geographical location may help clinicians in choosing the appropriate antimicrobial agent.

Objective : The objective of this study was to find out the pathogens in pediatric UTI and their antimicrobial susceptibility pattern.

Methods : A cross sectional study was done at Dhaka shishu Hospital during the period of Feb 2016 to Aug 2016. A total of 147 culture positive UTI patient were taken for analysis. Colony counts of these samples, were identified, and the profile of antibiotic susceptibility was identified. Here, samples with a colony count of $105 \mathrm{CFU} / \mathrm{mL}$ bacteria were considered positive.Twelve (12) antimicrobial agent were used for antimicrobial susceptibility testing.

1 Dr. Md. Atiqul Islam Registrar Dept. of pediatric Infectious Diseases \& Community Pediatrics Dhaka Shishu Hospital

${ }^{2}$ Dr. Jesmin Ahmed Coordinator, Vaccination Center Square Hospital Ltd. Dhaka

3 Prof. B H Nazma Yasmeen Professor \& Head Dept. of Paediatrics Northern International Medical College, Dhaka

${ }^{4}$ Dr. Mirza Md. Ziaul Islam Assistant Professor Dept. of pediatric Infectious Diseases \& Community Pediatrics Dhaka Shishu Hospital

${ }^{5}$ Dr. Nurun Nahar Resident Medical Officer Dept. of pediatric Infectious Diseases and Community Pediatrics Dhaka Shishu Hospital

Correspondence

Dr. Md. Atiqul Islam

Registrar

Dept. of pediatric Infectious

Diseases and Community Pediatrics

Dhaka Shishu Hospital

e-mail : roman.atique@yahoo.com

Result : Among 147 culture positive UTI patients Escherichia coli (E-coli) was found as the most prevalent 103(70\%) followed by Klebsiella spp. 13.6\%, Enterobacterspp 3.40\%, Pseudomonas 5.44\%, Staphylococcus Aureus 3.40\%, Enterococcus $1.36 \%$ and Proteus $2.72 \%$. The most effective drugs found against urinary isolates was Imepenum (97.27\%), followed by Colistin (94.55\%), Meropenum (93.87\%) and Amikacin (91.83\%). E.coli was moderately sensitive to Ceftraxone, Ceftazidime, Nitrofurantoin and Ciprofloxacin.

Conclusion: In this study, Imipenum, Meropenum, Amikacin and Colistin shown to be the most sensitive antibiotics for the UTI pathogen. Antimicrobial drug resistance is increasing among urinary pathogens. Therefore, empirical antibiotic selection should be based on knowledge of the local prevalence of bacterial organism and their antibiotic susceptibility in a specific area rather than on universal or even national guidelines.

Key words : UTI; Antibiotic susceptibility; Urinary Pathogens; Resistance, Sensitive.

Northern International Medical College Journal Vol. 8 No. 02 January 2017, Page 220-223

\section{Introduction}

UTI is the most common serious bacterial infection in infants and children both in community and hospital setting. It is an important cause of morbidity and mortality in children. ${ }^{1-3}$ Boys are more susceptible during the first year of life; thereafter the incidence is substantially higher in girls. ${ }^{4,5}$ Rapid diagnosis and prompt antimicrobial treatment are required to minimize the related complications, such as urosepsis, urolithiasis, and renal abscess, as well as the prevention of renal scarring and permanent renal parenchymal damage.

To achieve these aims an empirical antibiotic prescription is often endorsed even before the culture results are available. The Antibiotic resistance to UTI pathogens has been increasing worldwide, specially to commonly used antimicrobials. $^{6-8}$

The increase antibiotic resistance trends are likely to have important clinical implication for the empirical use of antibiotics. This knowledge of etiology and resistance pattern in specific geographical area will help the clinician to select appropriate antibiotic ${ }^{9-10}$. Reporting of antimicrobial susceptibility testing of the urinary tract is usually achieved $48 \mathrm{hr}$ following sampling, and therefore, in the majority of UTI cases, the treatment decision is empirical, being influenced by available data reflecting antibiotic resistance. For the initiation of antimicrobial therapy in UTI 
knowledge of the antimicrobial resistance patterns of common uropathogens in each region is essential to provide appropriate therapy. Hence, there exists a great need for antimicrobial resistance surveillance at the local, national, and international levels. The effect of resistant microorganism is obvious in hospitals and other healthcare facilities, when infections caused by the drug resistant microorganism. This results in a prolonged infectivity with related mortality and mortality especially among immune compromised patients. ${ }^{11}$

The aim of the present study was to determine the common causative organism of UTI and their antimicrobial susceptibility patterns of uropathogens among children subjected to urine culture at Dhaka Shishu Hospital, the largest children hospital in Bangladesh.

\section{Materials \& Method}

Study Design : This was a cross sectional study carried out in both inpatient and outpatient departments in Dhaka Shishu Hospital from February 2016 to August 2016. Total 147 urine culture positive patients were selected for the study. Clean catch midstream urine samples were collected from patients of suspected UTI samples then examined microscopically and were cultured on MacConkey agar plates and blood agar plates by calibrated loop method. UTI was considered by the presence of a pure bacterial growth of $>10^{5}$ colony forming units $/ \mathrm{mL}$ in children. Urine culture was considered as negative when bacterial growth was lower than $10^{3} \mathrm{CFU} / \mathrm{ml}$ (exclusion criteria). Growth of two or more bacterial species (polymorphic bacterial growth) was consider as an exclusion criterion.

\section{Anti bacterialsuceptibility testing}

The common 12 antibiotics used in the UTI, were used for susceptibility testing. These Antibiotics were amikacin (AK), nalidixi-

cacid (NA), ciprofloxacin (CP), cotrmoxzole (SXT), ceftazidime (CZM), ceftriaxone (CRO), imepenum(IP), meropenum (MP) and nitrofurantoin (FD), Cephradine (SD), azithromycin(AZ), colistin (CL) were used for susceptibility testing. In statistical analysis, bacteria with intermediate susceptibility were considered as resistant. The patients were interviewed using a pre-designed structure questionnaire to collect data and other relevant finding. Finally, the data were compiled and analyzed inMS Excel version 2010 and presented in tabular form.

Result

In this study, 147 Culture positive UTI cases were taken. Among them, $90(61 \%)$ were girls and 57 (39\%) were boys and 95 $(64.6 \%)$ were from outpatients and 52 (35.4\%) from inpatients. The most frequently isolated bacteria included E.coli (70\%), Klebsiella spp.(13.6\%), and Enterococcus spp. (3.40\%), Enterococcufaecalis spp (1.36\%), Enterobacter spp. (3.4\%), and Pseudomonas aeruginosa (5.44\%). Sex distribution of patients and the prevalence of significant bacteria shown in Table I and II

$\begin{array}{lccc}\text { Table I : Distribution of patients by sex of } & \text { Culture positive UTI } \\ \text { Age } & \text { Male } & \text { Female } & \text { Total } \\ 1-5 \text { yrs } & 37 & 60 & 97 \\ 6-10 \text { yrs } & 20 & 30 & 50 \\ \text { Total } & 57(39 \%) & 90(61 \%) & 147\end{array}$

Table II : Frequency and types of bacterial isolates. $(n=147)$. Bacterial Isolates

E. Coli

Frequency

Klebsiella spp.

$103(70 \%)$

Pseudomousaeruginosa

$20(13.6 \%)$

Enterobactor Spp.

$8(5.44 \%)$

Staph aureus

$5(3.40 \%)$

$5(3.40 \%)$

Protius Spp.

$4(2.72 \%)$

Enterococcufaecalis Spp.

$2(1.36 \%)$

Total $147(100 \%)$

Table III : Bacterial Isolates with number

\begin{tabular}{|c|c|c|c|c|c|c|c|c|}
\hline \multirow{2}{*}{ Antibiotic } & \multirow{2}{*}{$\mathrm{N}-147$} & \multicolumn{7}{|c|}{ Bacterial isolates with Numbers } \\
\hline & & E. Coli & Klebsiella spp. & Pseudomous aeruginosa & Enterobactor Spp. & Staph aureus & Protius Spp. & Enterococcus Spp. \\
\hline & 147 & 103 & 20 & 8 & 5 & 5 & 4 & 2 \\
\hline Amikacin (AK) & $\mathrm{S}$ & 90 & 13 & 4 & 2 & 1 & 2 & 2 \\
\hline Nalidixic acid (NA) & $S$ & 30 & 8 & 2 & 1 & 2 & 0 & 1 \\
\hline ciprofloxacin (CP) & S & 66 & 11 & 3 & 2 & 2 & 2 & 2 \\
\hline co-trimoxazole (SXT) & S & 34 & 5 & 0 & 0 & 0 & 0 & 1 \\
\hline ceftazidime(CTM) & $S$ & 53 & 8 & 3 & 2 & 1 & 2 & 1 \\
\hline ceftriaxone (CRO) & $\mathrm{S}$ & 84 & 14 & 4 & 2 & 5 & 3 & 2 \\
\hline imepenum(IP) & $S$ & 98 & 18 & 7 & 4 & 5 & 4 & 2 \\
\hline Meropenum(MP) & $\mathrm{S}$ & 95 & 16 & 7 & 4 & 5 & 4 & 2 \\
\hline nitrofurantoin (FD) & $\mathrm{S}$ & 75 & 9 & 4 & 3 & 2 & 2 & 1 \\
\hline Cefradine (SF) & $\mathrm{S}$ & 79 & 11 & 5 & 3 & 3 & 3 & 2 \\
\hline Azithromycin(AZ), & $\mathrm{S}$ & 51 & 8 & 5 & 2 & 2 & 1 & 1 \\
\hline Colistin (CL) & $\mathrm{S}$ & 97 & 16 & 6 & 4 & 5 & 4 & 2 \\
\hline
\end{tabular}


Table IV: Antimicrobial Susceptibility (\%) of Isolated Uropathogenic Bacteria

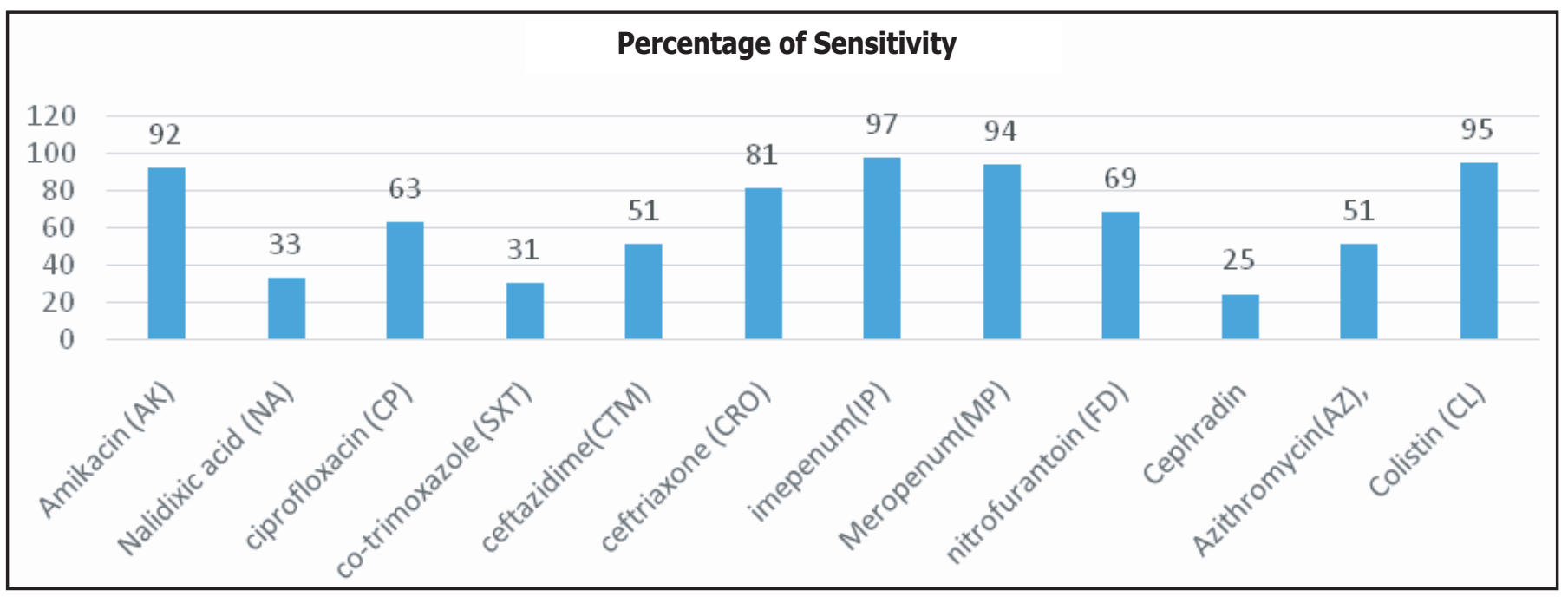

None of the organisms were found $100 \%$ sensitive to any of the tested antimicrobial agents. Most of the pathogens are sensitive to imepenum, Colistin, Meropenum and Amikacin and fairly sensitive to Ceftriaxone, Nitrofurantoin and Ciprofloxacin. This study shows, the common pathogens of UTI e.g E. Coli is less sensitive to Cephradine, Co-Trimoxazole, Nalidixic Acid, Azithromycin and Ceftazidime. All the isolated organisms were found almost resistant to Cephradine (73.49\%).

\section{Discussion}

This is a comprehensive study to estimate the most common uropathogens and their susceptability pattern in pediatrics. Uropathogen are gaining resistance at an increased rate to commonly used antimicrobial agents. The sensitivity pattern is changing day by day and it varies from hospital to hospital even in the same city and therefore from country to country. Constant survey of antimicrobial resistance is very important for empirical treatment of UTI. ${ }^{12-13}$ This study showed the prevalence of sensitivity and antibiotic succeptibility pattern of uropathogenic bacteria in a referral pediatric hospital, Dhaka shishu Hospital during 07 months period.

In different studies, E coli and Klebsiella spp. have been isolated as the most common pathogens responsible for UTI among children. ${ }^{14-15}$ In our study $E$ coil is still the most common (70\%) cause of UTI and the klebsiella being the second (13.6\%). In a study conducted in BSMMU by Abu salehahmed et al showed that the incidence of $E$ coil, Klebsiella spp, Enterobacter spp and Pseudomonas aeruginosa in UTI patients were $60.02 \%, 9.73 \%$, $11.38 \%$ and $4.04 \%$ respectively. ${ }^{16}$ Another study conducted in Bangladesh by Rahaman Farzana et al in 2009 reported thatthe frequency as for $E$ coil was $66.92 \%$ for Klessiella $13.45 \%$ Pro- teus $6.77 \%$ and Pseudomoas spp $6.77 \%$. In a study conducted in India in 2007 has shown that the distribution of urinary pathogen were as follows. E coil $63 \%$, Klebsiella spp $15.9 \%$ and Pseudomonas aeruginosa $5.30 \% .{ }^{17}$ Another study conducted at Border guard Hospital (BGB Hospital Peel khana Dhaka) by Lt Col. Syed Nurun Nobi et al in 2013 Showed that E-coli 63.26\%, Klebsiella $12.24 \%$ Proteus $2.77 \%$ and Pseudomonas spp $8.17 \%$.

In this study result of antibiotic susceptibility test reveal that no one urinary isolate were $100 \%$ sensitive to imepenum, meropenum, colistine, amicacin and E.coil which was sensitive to the above mentioned antimicrobials were $97.27 \%, 93.87 \%, 94.55 \%$ and $91.83 \%$ respectively. Previous study showed that the susceptibility of E.coli to Impenum ranged from $98-100 \% .{ }^{18}$ Now a days, globally the resistance of $E$. coil to Impenumis increases gradually. In recent years the sensitivity to Impenumhas been reported $80-96 \%$ in different study. ${ }^{19}$

In this study, most of the isolates were found fairly sensitive in Ceftriaxone (80.95), nitrofuration (68.70) co-trimoxazole (51.02) and ceftazidime (51.02). All the isolates showed poor sensitivity to Cephradine.

Limitation of this study : This study was done in a single center with limited number of sample and within a limited period of time.

\section{Conclusion}

This study provides valuable information regarding current prevalence of urinary pathogens and their antimicrobial susceptibility pattern. We suggest that empirical antibiotic selection should be based on knowledge of the local prevalence of bacterial organism and antibiotic susceptibility rather than on universal or even 
national guidelines for specific therapy. Considering this study findings imepenam, colistin and amikacin should highly sensitive to uropathogens, can be used for empiric treatment of UTI in our country at present time but the choice of definitive antibiotic should however be based on urine culture and sensitivity report.

\section{Acknowledgements}

The Authors would like to thanks the Microbiology laboratory staff and the junior doctors who helped to collect data for this research work, done at Dhaka Shishu (Children) Hospital and also grateful to them for their kind support during the study period.

\section{References}

1. LP Jadresic, "Diagnosis and management of urinary tract infections in children". Paediatrics and Child Health, 2010; 20(6): 274-278.

2. O Adjei and C Opoku, "Urinary tract infections in African infants," International Journal of Antim-icrobial Agents, 2004; 24(1): S32-S34.

3. F Mortazavi and $\mathrm{N}$ Shahin, "Changing patterns in sensitivity of bacterial uropathogens to antibiotics in children," Pakistan Journal of Medical Sciences, 2009; 25(5): 801-805.

4. Larcombe J. Urinary tract infection in children. BMJ 1999; 319:1173-1175.

5. Alper BS, Curry SH. Urinary tract infection in children. Am FamilPhys 2005; 72:2483-2488.

6. F. E. Abdullah, AA, Memon, MY, Bandukda, and M Jamil, "Increasing ciprofloxacin resistance of iso-lates from infected urines of a cross-section of patients in Karachi," BMC Research Notes, 2012; 5(1): 696-701.

7. A. Alemu, F Moges, Y Shiferaw, K Tafess, A Kassu, B. Anagaw, et al., "Bacterial profile and drug susceptibility pattern of urinary tract infection in pregnant women at University of Gondar Teaching Hospital, Northwest Ethiopia," BMC Research Notes, 2012; 5(1): 197-204.

8. G. Schmiemann, I Gagyor, E Hummers-Pradier, and J. Bleidorn, "Resistance profiles of urinary tract infections in general practice-an observational study," BMC Urology, 2012; 12(1): 33-38.
9. S. Farajnia, MY Alikhani, R Ghotaslou, B Naghili, and A Nakhlband, "Causative agents and antim-icrobial susceptibilities of urinary tract infections in the northwest of Iran," International Journal of In-fectious Diseases, , 2009; 13(2): 140-144.

10. N. Kashef, GE Djavid, and S Shahbazi, "Antimicrobial susceptibility patterns of community-acquired uropathogens in Tehran, Iran," Journal of Infection in Developing Countries, 2010; 4(4): 202-206.

11. Clinical Laboratory Standards Institute (CLSI). Performance Standards for Antimicrobial Susceptibility Testing; Nineteenth Informational Supplement (M100-S19). Wayne, PA: CLSI; 2009.

12. Nabi SN, Haider KMTS, Rahimgir M, Uddin MN, Shapla NR et al; "Current trends of urinary patho-gens \& their antimicrobial susceptibility pattern in a tertiary care hospital," JAFMC Bangladesh. (De-cember) 2014; 10(2):.

13. Hryniewicz K, Szczypa K, Sulikowska A et al. Antibiotic Susceptibility of bacterial stains isolated from urinary tract infection in Polland. J. Antimicrobchemother 2001; 47(6):773-80.

14. Farjana R, Sadia C, Mojibur R, Ahmed D, Anwar H. Antimicrobial resistance pattern of gram negative bacteria causing urinary tract infection, Stamford journal of Pharmaceuticals sci 2009; 2(1): 44-50.

15. Lutter SA, Currie ML, Mitz LB, et al. Antibiotic resistance patterns in children hospitalized for urinary tract infections. Arch PediatrAdolesc Med 2005; 159:924-928.

16. Salah AA, Ahmed SS, Ahmed M, Naser A, Ruhul A M. Changing Trends in Uropathogens and their antimicrobial sensitivity pattern. Bangladesh J Med Microbial 2009; 03(01); 9-12.

17. Tantry BA, Rahiman S. Antibacterial resistance and trend of urinary tract pathogens in commonly used antibiotics in khasmir Valley; West Indian med J 2012; 61(7): 43-44.

18. Anudumani $\mathrm{N}$, MallikaM,. Antibiotic resistance pattern in uropathogens in tertiary care hospital. Indian Journal of th practicing doctor 2007; 4(1): 41-45.

19. Mahmood MA Prevelance and antimicrobial susceptibility in urinary tract infection. Journal of Al-hahrainuniversity Baghdad. 2011;14 (4): 146-152. 